\title{
The Exploring of Mechanical Drawing Experiments and Practices Teaching Architecture Constructing: In Agricultural Machinery Professional Case
}

\author{
Zhen Bo Bao ${ }^{a}$, Xiao Shan Zhao ${ }^{b}$, Shu Huan $\mathrm{Li}^{\mathrm{c}}$ and Lei Yang ${ }^{\mathrm{d}}$ \\ Engineering and Technology College, Tianjin Agricultural University, Tianjin 300384, China \\ a*baozhenbo@sohu.com, bxx1024@163.com, chblshh@163.com, dyanglei2004@yeah.net
}

\begin{abstract}
Keywords: Machinery Drawing; Experiment and Practice; Exploring; Theory and Practice; Space Imaginative Faculty
\end{abstract}

\begin{abstract}
Mechanical Drawing is a professional technology foundation course with the characteristics of theory and practice. According to the coherence between Mechanical Drawing course knowledge and the follow-up courses, the practical principle of Mechanical Drawing course knowledge, and the characteristic of the mechanical drawings as engineering technology language, the experiments and practices links of Mechanical Drawing are divided into two parts of curricular and the extracurricular, and the Mechanical Drawing experiments and practices architecture are built. Through the teaching practice of Mechanical Drawing experiments and practices links, the learning enthusiasm and initiative of students are effectively stimulated, the quality of drawing teaching are improved, the comprehensive draw ability of students are strengthened, and the aim of training innovative talents are achieved.
\end{abstract}

\section{Introduction}

Mechanical Drawing is a compulsory professional and technical course of mechanical engineering, and related or similar professional. Mechanical drawings are composed by graphics, symbols, words, and digital and so on, is a technology language of mechanical engineering, a tool for technical exchange of technical personnel, and is important technical information for design, manufacturing and product use. Mechanical Drawing course knowledge is not only used in subsequent experiments and practices links of related professional courses, and continues to be widely used in practical work. Mechanical Drawing in different teaching systems, the curriculum for Engineering Drawing, Engineering Graphics, Mechanical Drawing + AutoCAD, and Geometry and Mechanical Drawing, etc. Currently, in our school Agricultural Machinery, Measurement and Control, New Energy, Mechanical and Electrical, Food Science, Biological Engineering, Environmental Science and other professions all set Mechanical Drawing course. The purpose of course teaching is to train students spatial imagination and thinking ability, so that students master the technology of reading and drawing mechanical drawings; and through subsequent training of relevant course experiments and practices links, as well as organizing and directing students to participate in innovation and entrepreneurship competition, to achieve the goal of applied innovative talents training. In the teaching practice, deeply understood that to achieve the above teaching purpose, must strengthen the Mechanical Drawing experiments and practices links [1,2].

\section{The Importance of Strengthening Mechanical Drawing Experiments and Practices}

Mechanical Drawing with strong theory, practice and profession, and covers a broad range of knowledge. Drawing knowledge is not only play a very important foundation role on the learning of subsequent professional courses, and mechanical drawings as an communication tools of engineering technology personnel, are widely used in engineering practice. Based on different professions, Mechanical Drawing course is set in the first semester, second semester or third semester, etc. Due to lack of space imagination and related engineering background knowledge, students feel boring and have difficulty to learn and understand the drawing course knowledge. After years of courses teachers 
group teaching practice, fully aware that the Mechanical Drawing experiments and practices are an important guarantee for students to master the courses content of Mechanical Drawing, and an indispensable teaching link to train engineering technology personnel and applied creative talents [2].

\section{The Construction of Mechanical Drawing Experiments and Practices Teaching Architecture}

In our school Agricultural Machinery profession for example, describes the building situation of Mechanical Drawing experiments and practices links architecture. The Mechanical Drawing experiments and practices of Agricultural Machinery profession are divided into two parts of curricular and extra-curricular, shown in Fig.1 [1]. In Mechanical Drawing curricular 16 hours experiments, include two hours of Basic Cognition experiments and 14 hours of Combination Model Drawing experiments. In the extra-curricular, according to the coherence between curriculum knowledge, and practicality of mechanical drawing, the Mechanical Drawing course experiments and practices links are integrated into the unified planning of professional courses experiments and practices links. In each extra-curricular experiment and practice, usually arrange 6 to 60 hours, strengthen the application of mechanical drawing knowledge, and arrange drawing tasks, and clear drawing workload and quality assessment. The specific content, requirements and term arrangements of Mechanical Drawing experiments and practices links are shown in Table $1[3,4]$.

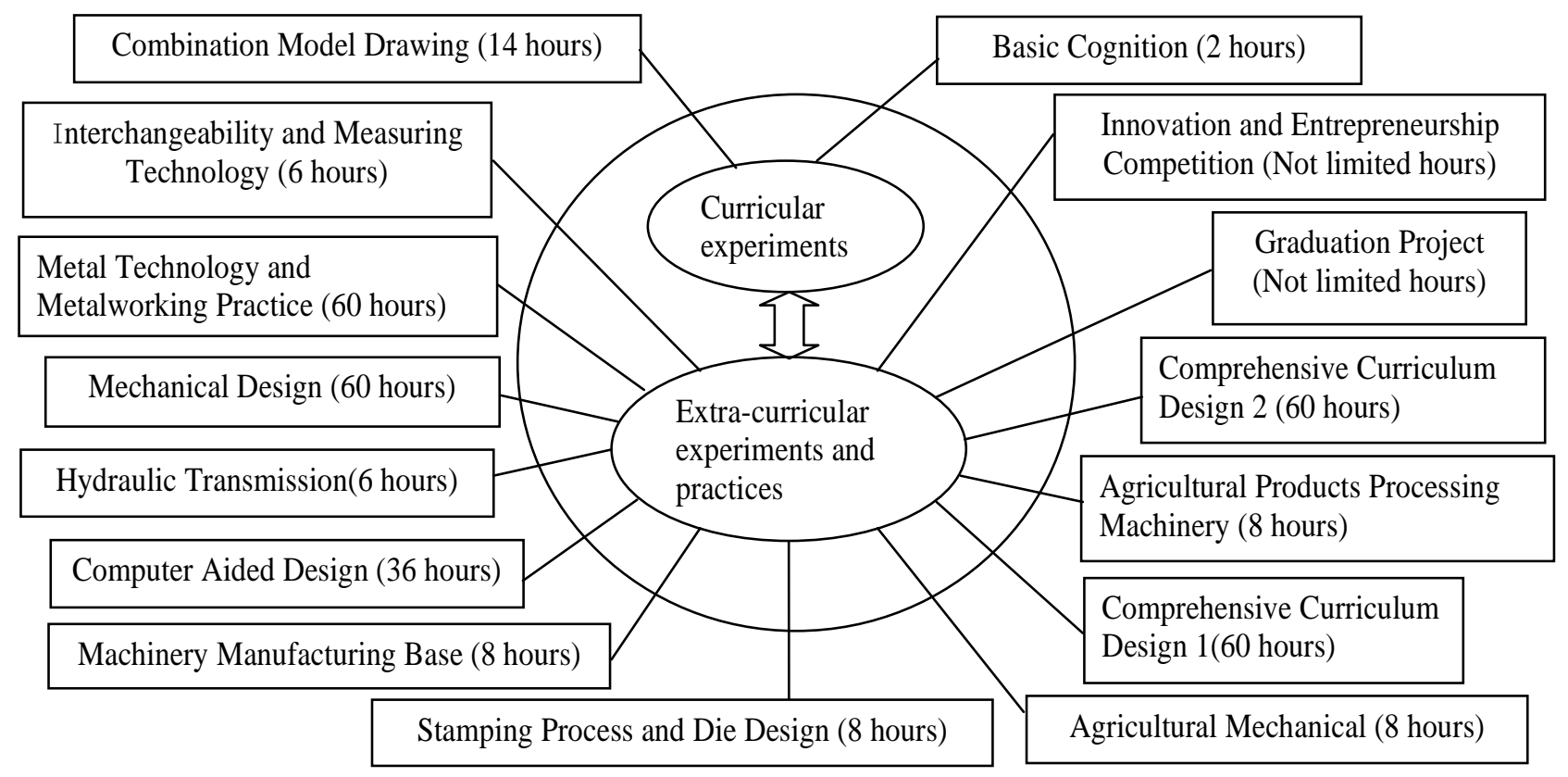

Figure. 1 The architecture of Mechanical Drawing experiments and practices links

\section{The Effectiveness after the Implementation of Mechanical Drawing Experiments and Practices Links Teaching System}

Effectively Stimulated Students' Enthusiasm and Initiative of Learning. The implementation of Mechanical Drawing experiments and practices links improved students' interest in learning, enabled students to study from passive to active. In the experiments and practices, students actively and independently learned, solved the problems encountered in experiments and practices, deeply understood theoretical knowledge, and cultivated the habit and ability of independent learning. In addition, students in the learning process, experienced the happiness of applying knowledge, not only no longer produced mental weariness to learn mechanical drawing, but also played a positive role for learning subsequent related course. 
Improved the Quality of Teaching, and Enhanced the Capabilities of Drawing. Mechanical Drawing course content includes descriptive geometry, basic drawings and mechanical drawings. Drawing geometry requires students to master the basic principles and methods of orthographic, graphic space geometry, graphic simple geometric space problem, which requires students to have a strong spatial imagination and thinking skills. Through the Basic Cognition experiments and Combination Model Drawing experiments, visually contacted solid model, guided students to combine the observation, spatial analysis and imagination, analyzed and studied the relationship between the object and the projection, and gradually developed students' spatial imagination, thought and analysis. Basic drawing requires students to understand the basic provisions of Mechanical Drawing and Technical Drawing national standards, and use the drawing tools and instruments to draw. The theory, knowledge and skills of basic drawing are guidelines and basis to learn drawing and reading mechanical drawings, so must learn well this part of knowledge. Mechanical drawing is the practice and application of drawing geometry and basic drawing, which requires students to master the basic ability to draw and read parts and assembly drawings of common components. Through the tasks of extra-curricular experiments and practices, such as design, assembly and disassembly, surveying and mapping, the application of computer aided design software for drawing $2 \mathrm{~d}$ graphics and $3 \mathrm{~d}$ modeling, and drawing parts and assembly drawings and so on, which are contributed for students to familiar with and master the course content, training students' comprehensive ability of drawing and reading mechanical drawings [5, 6].

Participating in the Contests, Achieved the Cultivation of Innovative Talents. Applying the knowledge of Mechanical Drawing, Mechanical Principles and Design and so on, through the improved design of assembly and disassembly, surveying and mapping, and the innovative design, to participate in science and technology innovation contests, which are the necessary extracurricular practices links to develop students' innovative consciousness and ability, to enhance students' engineering awareness and engineering literacy, to cultivate students' innovative ability, teamwork and communication skills, and to achieve the cultivation of innovative talents. In recent years, the course teachers group actively guided students to participate in the National Three-dimensional Digital Innovation Design Competition, Tianjin University Student Engineering Training Comprehensive Ability Competition, Tianjin University Student Extracurricular Academic Science and Technology Work Competition and other activities, and achieved excellent results. Fig. 2 and Fig. 3 is students' creative works $[7,8]$.

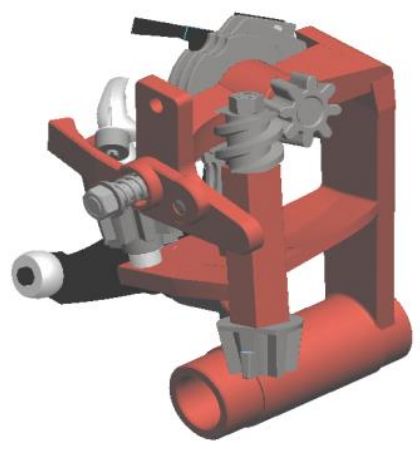

Figure. 2 Knot machine

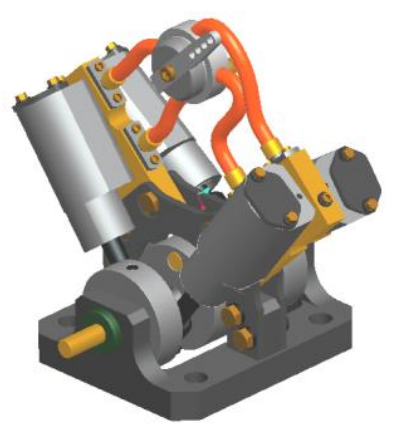

Figure. 3 Multi-cylinder swing steam engine 
Table 1 The teaching system of Mechanical Drawing experiments and practices links $[9,10]$

No.

The experiments and practices links (Class hours), the contents and requirements of experiments and practices links, and the term of curriculum

Basic Cognition (2 hours): Watch mechanical device model in the mechanical drawing and mechanical design model room, visit the machinery manufacturing and processing workshop. Acknowledge the drawing basic theory and national standards, and understand the relationship between drawing, mechanical equipment and machinery processing. 1 semester.

Combination Model Drawing (14hours): Draw three view of single and complex combination model, cultivate students' space thinking ability, and master the drawing of entities three-view. 1 semester.

Interchangeability and Measuring Technology (6 hours): Basing surveying and mapping, apply mechanical drawing knowledge to draw mechanical drawings, mark dimension tolerances and geometric tolerances, and acquire the knowledge of interchangeability and measurement techniques. 2 semester.

Metal Technology and Metalworking Practice (60 hours): By reading mechanical drawings, understand turning, milling, grinding, forging, welding, casting and other machining processes, and master the basic skills of turning, milling and other processes. 3 semester.

Mechanical Design (60 hours): Determine the design of transmission scheme, design reducer, shafts and gears and so on, and draw parts and assembly drawings. 4 semester.

Hydraulic Transmission (6 hours): Assemble and disassemble, survey and map hydraulic transmission device, and draw parts and assembly drawings and so on. 5 semester.

Computer Aided Design (36 hours): Combining drawing knowledge, apply computer aided design software technology to draw parts and assembly drawings, etc. 5 semester.

Machinery Manufacturing Base (8 hours): Assemble and disassemble, survey and map typical common parts and components, draw parts and assembly drawings and so on, and apply the Pro/E and other three-dimensional graphics software modeling. 6 semester.

Stamping Process and Die Design (8 hours) :Assemble and disassemble, survey and map parts and components of stamping die, draw parts and assembly drawings of stamping die, and apply the Pro/E and other three-dimensional graphics software modeling. 6 semester.

Agricultural Mechanical (8 hours): Assemble and disassemble, survey and map agricultural machinery, draw parts and assembly drawings, and apply the Pro/E and other three-dimensional graphics software modeling. 6 semester.

Comprehensive Curriculum Design 1(60 hours): Assemble and disassemble, survey and map pumps, two stage reducer and other devices, draw parts and assembly drawings, and apply the Pro/E and other three-dimensional graphics software modeling. 6 semester.

Agricultural Products Processing Machinery (8 hours): Assemble and disassemble, survey and map agro-processing machinery, draw parts and assembly drawings, and apply the Pro/E and other three-dimensional graphics software modeling. 7 semester.

Comprehensive Curriculum Design 2 (60 hours): Assemble and disassemble, survey and map grinder, and diesel and so on, draw parts and assembly drawings, and apply the Pro/E and other three-dimensional graphics software modeling. 7 semester.

Graduation Project (Not limited hours): Apply the knowledge of drawing, mechanical principles and design, design mechanical and electrical products, draw parts and assembly drawings, and apply the Pro/E and other three-dimensional graphics software modeling. 8 semester.

Innovation and Entrepreneurship Competition (Not limited hours): Applying the knowledge of drawing, mechanical principles and design and so on, assemble and disassemble, survey and map, and innovative design mechanical and electrical products, draw parts and assembly drawings, and apply the Pro/E and other three-dimensional graphics software modeling. Not limited semester. 


\section{Summary}

With the deepening reform of higher education teaching, and the society's increasing demands for professionals, the employment pressure of students and talents competition gradually increased. Mechanical Drawing as an important basic course plays an important role in the process of personnel training. After years of course teachers group continuous exploration, the teaching system of Mechanical Drawing experiments and practices links are built, and achieved good teaching results. With modern knowledge update and the society's increasing demands for innovative talents, the construction and perfection of Mechanical Drawing experiments and practices links teaching system is bound to be continued and sustained work. For example, with the adjustment of professional courses, drawing course teachers should actively involve in Mechanical Drawing experiments and practices links, participate in the formulation of drawing workload assessment contents and methods, and strengthen the application and assessment of drawing knowledge in engineering practice, innovation competition, graduation design and other practical links.

In short, drawing course teachers should in line with strong social responsibility and teaching mission, with unremitting efforts to make greater contributions for curriculum development, academic development and nurturing of creative professionals.

\section{Acknowledgements}

This work was financially supported by the Project of Tianjin Agricultural University Mechanical Drawing Excellent Courses (201304).

\section{References}

[1] H.X. Song: Journal of Graphics, Vol. 34 (2013) No.3, p.142-147. (In Chinese)

[2] Q. He and Y.C. Zhang: Journal of Liaoning University of Technology, Vol. 14 (2012) No.6, p.113-114. (In Chinese)

[3] L. Wang, J.P. Zhao and J.M. Li: Journal of Anhui University of Technology (Social Sciences), Vol. 30 (2013) No.6, p.114-115. (In Chinese)

[4] J.H. Wang, Y.X. Hao and X.M Li: Journal of Engineering Graphics, Vol. 31 (2010) No.5, p.138-141. (In Chinese)

[5] L. Li: Mechanical drawing animation technology Mechanical drawing animation technology (MS., Changan University, China 2012), p.1-3. (In Chinese)

[6] Q. Ding, L.Y. Han and Y.H. Sun: Mechanical Management and Development, Vol. 25 (2010) No.3, p.134-135. (In Chinese)

[7] C.X. Li: Career Horizon, Vol. 10 (2014) No.2, p.100-102. (In Chinese)

[8] J. Lin: Tsinghua Journal of Education, Vol. 32 (2011) No.2, p.47-55. (In Chinese)

[9] Y.G. Yang and L.L. Gong: Engineering Graphics (Beijing University of Posts and Telecommunications Publications, China 2013). (In Chinese)

[10] J.Y. Zhang, H. Zhang and Y.H. Jiao: Mechanical Drawing (Beijing Institute of Technology Publications, China 2013). (In Chinese) 